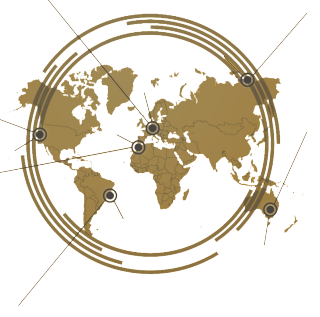

\title{
Assessing the Effectiveness of Mobile-Application Technology: A Project-based Learning
}

\author{
Sariani Sariani, Yaningsih Yaningsih, Mutia El Khairat* \\ English Department, Politeknik Negeri Padang, Indonesia
}

In the development of technology and its advances in this industrial revolution 4.0 era, the graduates of vocational higher education institution are required to have a ready to use skill as demanded by the job market. This study aimed to investigate the effectiveness of utilizing mobile applications regarding vocabulary acquisition which occurred within a learning process. It was a project-based learning (PBL) performed during the supervision time of the student' final project applying dictionary applications; The Free Dictionary and Dictionary.com. A mixed method approach was implemented where the data for the quantitative study was collected from the comparison of Vocabulary Size Test (VST) Monolingual-Version A which were carried out prior to and after the PBL. Moreover, the qualitative data was obtained from semi close-ended questionnaire, and open-structured interview. The result shows the superiority of using the mobile apps through this projectbased process and at the same time the apps provide contextualized problem-solving environment to their users.

Keywords: vocabulary size test, mobile application, project-based learning

\section{INTRODUCTION}

Industrial Revolution (IR) is a concept established by a German Economist; Professor Klaus Schwab in his book entitled "The Fourth Industrial Revolution" (Xu et al., 2018). This concept consists of four stages which have been starting from the $18^{\text {th }}$ Century up to recent times carrying out changes in life and human performance. In this $20^{\text {th }}$ Century in line with the development of the technology, there have been many inventions on modern communication tools which can change people's life style which indirectly change their mindset in innovating (Rachman, 2018). People have to be opened and prepared for new strategies and to deal with this IR 4.0 challenges, they have to understand that there are advances in technology where generation will be more attached onto the use of smart phones and the apps than previous years (Hussin, 2018). As the competition becomes competitive in this IR era 4.0 therefore there should be improvement made in all sectors of life particularly in Human Resource (HR), where education system is included. In education world, there are three fundamentals changes that should be made. The first one is on how to change the mindset of the students, the second one is on how to change the learning method and the way of learning in line with the era development, and the third one is on how the educational institution is able to shape and improve the creativity and innovation talent of the students. These changes are adequate for any levels of educational system, especially higher education institutions, which at recent times are expected to produce graduates who can compete in the global market (Ibrahim, 2018).

Citation: Sariani S, Yaningsih Y and El Khairat $M$ 2020) Assessing the Effectiveness of 
Innovation interruption in this IR 4.0 era has generated the educators to incorporate their learning to be more customized, hyper, intelligent, portable, worldwide, and virtual. In this regard, they have to incorporate the computerized teaching method and smart classroom into their instructing and learning method, and develop a 4.0-ready environment fitting to institutional contexts (Hussin, 2018).

Politeknik Negeri Padang (PNP) is one among those vocational higher education institutions which is responsive in responding to the IR 4.0 challenge. In order to improve the quality on knowledge of its graduates, PNP has made some transformations in adjusting its learning facilities and infrastructures related to information technology, internet, big data analysis, and computerization, and so does English Department, PNP. This department focuses its learning in translation and broadcasting areas. Nowadays, the challenges faced by these areas are on how to deal with the expansion of IR 4.0 by utilizing the developing of technologies, and on how to lessen the dependency on human force (Bonciu, 2017). In addition, an educational institution should also be able to develop their students' ability to rapidly adapt and be opened for new strategies where at the same time enhance the performance of the system and the process (Hussin, 2018). In translation area, the use of technology has become a necessity, mobile phone as one of them. At present, its use increases the potential of instructions and facilitates students' language learning in terms of vocabulary as well as receiving learning materials anywhere and anytime through the wireless telecommunication and internet can be perceived from mobile technology (Chanprasert and Hnin, 2013; Lan and Sie, 2010).

Regarding translation project, it is beneficial for the students to enhance their vocabulary acquisition by engaging the students into their project work. In accordance with this translation project, the project-based learning $(\mathrm{PBL})$ taken is not the supplementary approach, it is the basis of the project itself (Bell, 2010). By performing PBL, it situates the students in realistic, contextualized problem solving environments bridging the phenomena the students perceived in the classroom and reallife experiences being a translator (Blumenfeld et al., 2011). Designing and carrying out project for the learners to develop their vocabulary size is considered decisive as the final product of their project is depended upon the amount of the words they know and the depth knowledge of them (Yaningsih et al., 2018).

\section{Education in Industrial Revolution 4.0}

As the era emerges, the landscape of educational 4.0 technology is developed as well. In addition to stressing the challenges faced by the students in this IR 4.0 era, teachers play a significant role in providing guidance to their pupils in using applications (apps) in their mobile phone responsibly and beneficial for their available learning time outside of class to acquire specific disciplinary knowledge and skills in language learning (Steel, 2012; Traxler, 2010). This can be applied to each stage of educational systems starting from Senior High School Level (Grade 7) up to higher education institution. Recent days, to have a mobile phone which is connected and has the access to the internet is commonly found in Indonesia even though this country is still considered as one of developing countries in the world. Many students can afford to have the cellular phone which is connected to internet. The more develop the technology is the cheaper its price, and its use has been surpassing the use of laptop.

In responding to this IR 4.0, Education 4.0 should have nine emerging trends regarding innovation and general shift of the world of learning (Fisk, 2017; Hussin, 2018; Lasse, 2019). First is 'Diverse time and place' where the opportunity for the students' learning process can occur not only in the classroom but also outside the classroom at different times by utilizing e-learning tools. Second is 'Personalized Learning' where each student is responsible for their own individual learning process. This behaviour can create positive learning experience of each student which leads to higher self-confident. Third is 'Free choice' where the student can decide their learning process by utilizing the tools, programs, and/or techniques which they consider adequate in enhancing the process. Fourth is 'Project based' where the student can learn and implement the skills of organizational, collaborative, and time management in shorter terms to a varied situation. Fifth is 'Field experience' where the student is exposed to more real-world working experience for example internship programs, mentoring projects, and collaborative projects. Sixth is 'Data interpretation' where the student can learn more about data interpretation and how to apply their theoretical knowledge to numbers and human reasoning to come to a logic decision based on sets of data. Seventh is 'Exam will change completely' where the assessment for the student will be carried out during their learning process, in contrast to previous conventional platforms. Eight is 'Student ownership' where the student' opinion is taken into account in designing and updating curriculum. Ninth is 'Mentoring will become more important' where autonomous learning and teacher as a facilitator become priority in order to make the student in control of their learning process.

\section{Language Learning in 21st Century}

At present, the students at higher education institution ranged between 18 and 23 year-old, where they are known as the Generation-Z (gen-Z) where their learning preference has been shifted to the use of technology. They are fully engaged into their learning process by welcoming challenges and responsive to their learning environment. Since these generations are so much into technology, learning by using digital tools and at places out of the classroom interest them as they can collaborate and have interactive learning process with their peer and/or group discussion anywhere and anytime (Hussin, 2018; Kozinski, 2017). By having this peer/ group discussion, these students can track their own learning process, whilst the teachers place themselves as the facilitator within this process. 
It can be said that by integrating this technology; digital tools into the students' learning process is one of the ways in preparing this generation to succeed in the Fourth Industrial Revolution (Hussin, 2018).

Notably for English language learning, there are many free downloadable apps which can profit the students in developing their vocabulary. Per January 2012, there have been 775,000 apps which are available and advantageous during the translation process, like The Free Dictionary, and Dictionary.com, as both apps containing not only the word' definition, its synonym, and antonym, but also the word' suffixes, prefixes, and root of the word, together with the sample sentences of the word' use (Deng and Trainin, 2015). These The Free Dictionary and Dictionary.com apps can advance the students' search and choices to look up when they encounter unfamiliar word, particularly when they cannot guess the unknown word through the context clues. To add, these apps can save their time as well compared to the hard copy one as they can find and confirm the guessed word, and concurrently enrich their knowledge into deeper level through authentic sample sentences by referring to these dictionary apps at hand (Deng and Trainin, 2015). Nevertheless,

Previous studies have highlighted the effectiveness on the concept of language learning via mobile technology as it has assisted the students in learning the language on all skills, particularly regarding the vocabulary acquisition (Stockwell, 2010; Zhang et al., 2011). In addition, one of the significant effects of this learning tool was it increased the students' learning motivation to be more independent (Suwantarathip and Orawiwatnakul, 2015). Besides, for the students, the availability, comfort of this mobile phone, and the cost-free to download the useful applications becoming one of their alternatives in acquiring new vocabulary.

\section{Project-based Learning}

Project-based learning (PBL) is considered as innovative approach in the $21^{\text {st }}$ century (Bell, 2010) where its core idea is that the students are actively involved within a project in acquiring and applying new knowledge in terms of problem solving by stimulating their interest and "need to know" questions which lead their critical thinking aspect (David, 2008; Efstratia, 2014). It is a teacher-facilitated where the teachers play their role as the facilitator, the one who coach, work with the students to manage significant questions, and guardedly assess what the students have learned through the experience. This PBL can take in both places inside or outside the classrooms, and is adaptable for different types of learners as it requires the students to choose the project, benefit the advantages of technology (Larmer and Mergendoller, 2010), work and communicate collaboratively to respond to a complex question, problem and to achieve the challenging project David (2008).

Likewise, Bell (2010) pointed out that by engaging the students to work collaboratively with their teachers within a project, it can help the students to reflect the skill and competence that they have, while at the same time empowering viable technologies which are useful for them. To this extent, PBL has been widely accepted as an effective teaching method as it can decrease the students' anxiety, and at the same time increase the students' learning quality by producing authentic product at the end of the project compared to conventional teaching method. Nevertheless, the assistance from the teachers are adequate when the students use the developed technology like mobile applications as the tool in conducting their project (Efstratia, 2014).

\section{Translation Learning}

Robinson (2012) stated that the study of translation and the training someone to be a professional translator is an integral part. The more developed the era, the higher the needs on the new approaches of this translation learning. At present, there are pedagogical assumptions which have been widely accepted that if one who wants to be a professional translator they should do many practices in translation, since experiences in translating cannot be replaced by anything else. By working on many translation projects they can enhance their skills and ability in translation as they can learn from the errors detected within their works, even though for some cases these errors can damage the process. Therefore, educators play significant role in providing the training to their students, so they can be able to accelerate the process to make them faster in their speed of learning and translating effectively and accurately. In translation world, besides being accurate in translating the source language to target language, a translator is also expected to work in a very limited time. The conducive learning environment between the students and the teachers, and making the benefit of advances facilities and infrastructure become two out of seven factors that must be acquired by the students in translation learning (Hanifah, 2016).

Therefore, by providing the students with the real-life experience implementing the PBL, they are expected to be familiar with the work rhythm as a professional translator. A translator can be seen from two perspectives where first is as a professional who work setting a mindset of user-oriented approach, and the second one is a professional who is responsible for his work and their field of knowledge. Therefore, to be a translator who is professional in their field, one is required to have reliability, timeliness, and cost onto themselves (Robinson, 2012), and these three points can be achieved when they are well-experienced. Arranging a translation project on the students might establish their vocabulary learning and development (Boustani, 2019).

Needless to say, over the years the students at English Department, PNP who focused on translation for their Final Project experienced hardship in conducting their project due to limited vocabulary size they had. Thus, this paper was intended to investigate how can a PBL for students' final project in translation by utilizing technology-based learning tools; 
The Free Dictionary and Dictionary.com somehow became effective regarding their vocabulary acquisition, and developed their understanding on unknown words they encountered while doing the project.

\section{METHODS}

A mixed method of Quantitative and Qualitative was applied within this study where Vocabulary Size Test (VST) Monolingual 20,000 Version A was utilized for the Quantitative, and a semi close-ended questionnaire and open-structured interview were for the Qualitative one. Hence, the data obtained from the two methods applied would be interpreted descriptively (Mcdonough and Steven, 1997).

\section{Participant}

The participant who took part in this study was a semester sixth student of English Department, Politeknik Negeri Padang (PNP) who was carrying out his Final Project (FP) focusing on translation area. His proficiency level referring to Common European Framework of Reference (CEFR) for the language learner was at the Level A2-Basic User. Prior to the study, the participant received 'human consent' (Mackey and Gass, 2005) along with the procedure of this study, and the participant could withdraw his participation at any convenient time.

\section{Instruments}

There were four instruments applied within this study, the first one was VST Monolingual 20,000 Version A, the second one was online dictionary apps; The Free Dictionary and Dictionary.com, the third one was close-ended questionnaire consisting of 10 questions, and the fourth one was interview consisting of four open-structured questions. The first instrument was the VST Monolingual 20,000 Version A retrieved from Paul Nation web http://www.victoria.ac.nz/lals/about/staff/pa ul-nation was administered two times; prior to and after the process of conducting the FP using the similar version. This test was presented in a written form, consisted of 100 multiple choice questions and concerned on measuring the productive vocabulary knowledge particularly in writing whether the participant can provide a word form to express a meaning.

The second instrument was the dictionary apps which were downloaded free of cost into the participant' mobile phone; The Free Dictionary and Dictionary.com. Both of these dictionaries are reliable and trusted in developing vocabulary and assisting the learners in the translation process (Deng and Trainin, 2015). For the third instrument was a semi close-ended questionnaire consisting of 10 questions. This questionnaire was administered to the participant right after the process of the translation completed. The questions were focused on the perception of the participant during the translation project using the apps. Whereas, for the last instrument was the interview which was implemented using open-structured questions consisting of four major questions. This interview was recorded and then transcribed by the researchers. This interview's result was aimed to enrich and strengthen the main data obtained from the VST.

\section{Data Collection and Data Analysis Technique}

The 'Human Consent' and the procedure of the study were handed out and explained to the participant before the study was performed, so the participant understood the design of the study and what the obligation he should fulfilled upon his agreement to participate.

Preliminary, the data was collected through the VST Monolingual 20,000 Version A given to the participant aiming to determine his starting vocabulary size. Then, the translation's project was carried out by the participant utilizing the dictionary apps for three months duration. Finishing this project, another VST test was given to the participant, the similar version of questions' test to the early one taken. The result of these two tests then was compared and regarded as the main data.

Semi close-ended questionnaire and open-structured interview were conveyed to the participant in order to support the previous data obtained providing unique insight for this study. The semi close-ended questionnaire consisted of 10 questions and was designed to acknowledge the participant's viewpoint on the apps utilized during the translation project. The questions were in the form agree and disagree with the statements made and the reason for choosing either option. The questionnaire was administered based on his convenient time and place, so that he could manage to provide fruitful information referred to the questions being asked.

Correspondingly, the open-structured interview session was conducted in order to have deep-insights of how he views the implementation of using the apps in terms of translation project, and how is the growth of his skill in translation and vocabulary acquisition. Then, the data obtain through the whole process of data collection was presented descriptively. As an addition, the participant' result of translation which had been transcribed into English by the researchers was also analyzed as a supporting data.

\section{RESULTS AND DISCUSSION}

\section{Vocabulary Size Test (VST)}

The multiple choice VST Monolingual 20,000 Version-A was carried out to the participant before and after the project-based learning within the range of three months without changing the version. Each question of this 100-question was demanded the participant to understand the meaning of a word, and to find its synonym provided with context within as a guidance among the four available answers. The earliest score obtained from this participant was 45 out of 100, and the latest VST score was 64 . It can be seen that the participant's VST score was increased after engaging him with the mobile dictionary apps; The Free Dictionary and Dictionary.com within his translation project by nine points. 
Nevertheless, it was a slight improvement of the answer made by the participant, referring to the test questions and the answers' choices starting from No. 60 until the rest of the questions, it was shown that the vocabulary used were lowfrequency words where rarely applied by almost every language user. The learning for these low-frequency words should be started from the teachers by providing the learners with strategies to acquire these words while learning the high-frequency words, like guessing from the context clues, using vocabulary cards and dictionaries, and using words part to help remember words (Nation, 2008) which should be repeated to a higher degree in any task given. Seen in Figure 1 the low-frequency words question in the VST. The words 'didactic', 'cranny', and 'lectern' were extremely hard to be guessed their meaning just from the context given.

$$
\begin{aligned}
& \text { 60. didactic: The story <is very didactic }>\text {. } \\
& \text { a tries hard to teach something } \\
& \text { b is very difficult to believe } \\
& \text { c deals with exciting actions } \\
& \text { d is written with unclear meaning } \\
& \text { a desk made to hold a book at a good height for rea } \\
& \text { b table or block used for church ceremonies } \\
& \text { c place where you buy drinks } \\
& \text { d very edge }
\end{aligned}
$$

FIGURE 1 | Questions in Vocabulary Size (VST) Monolingual 20,000 Version A

Therefore, by engaging the participant with project-based learning (PBL) within this translation project, the driving questions as presented in Figure 1 that the student encountered in the earliest VST test encouraged him to acquire an understanding of key principles and concepts of investigating and seeking resolutions to problem becoming accustomed to the contextualized problem-solving environment (Blumenfeld et al., 2011). Even though the increase on the correct number of the two VST taken is not that significant, there is an evident that the participant had taken the practice performed during the PBL into different learning situations.

\section{Semi-closed-ended questionnaire}

Another point worth noting that the finding mentioned above was supported by answer' obtained from the semi-closedended questionnaire conveyed to the participant after the translation project completed. Out of the 10 questions administered, mostly the participant was in the agreement of what have been stated in. In the preliminary answers, he agreed using dictionary both hard copy and online web based or mobile phone apps for any works of translation had become a great assistance for the learners in looking for the meaning of a word, understanding context through several definitions of word provided, and understanding the whole sentence and/or paragraph through information given within.

Moreover, it can be determined from the answers given for the rest of the statements that the preference of employing mobile dictionary app was greater than the hard copy one, particularly the Free Dictionary and Dictionary.com for any translation projects in the coming future. It was due to the portability of this mobile phone which could be easily carried and used anywhere to support the translating process besides its efficiency. Hence, dictionary apps on personal mobile phone can provide learning affordances and open new opportunities to personalize the learning as the user can carry out selective scaffolding based on individual preferences and personal learning progress. Being familiar with and aware on the function of two dictionary apps mentioned above are surely can be potential for the learner to assist them in learning (Deng and Trainin, 2015; Steel, 2012).

The vocabulary learning that can be obtained through the mobile dictionary apps as seen in Table 1 showing that these dictionary apps allow learners to find the designated words with the appropriate use in terms of context and grammatical forms as they afford the learners not only with the word' extensive definitions, pronunciations, and etymologies but also with its authentic sample sentences and its synonymous words' usage.

The participant also highlighted the convenience and flexibility of using both dictionary apps in his mobile phone to gain time efficiencies, and to give the feelings of freedom to the students on their learning process (Chanprasert and Hnin, 2013). For the questionnaire' statement: 'I can improve my ability in English by using online (downloadable) dictionary apps in mobile phone instead of printed dictionary', the answer' made was: 'Yes, agree, because it is more fast to be searched than using printed dictionary. Besides, online dictionary is easier and more attractive instead of printed dictionary'. It can be comprehended that any learning tasks can be achieved quickly and easily, well-spent time for language acquisition in accessing information in need (Steel, 2012), well-managed in their own learning style based on their own learning speed (Chanprasert and Hnin, 2013; Suwantarathip and Orawiwatnakul, 2015).

\section{Open-ended Interview}

The involvement of mobile dictionary apps in language teaching related to its portability, social connectivity, context sensitivity, connectivity, and individualizing instruction Deng and Trainin (2015) besides its physical characteristic, and output capabilities (Basal et al., 2016) undoubtedly was a strong theme of the data obtained in this research. By employing this mobile dictionary apps, students took control in acquiring knowledge, to achieve the learning goals that they had set, and to make their learning process becoming meaningful. 
TABLE 1 | 1 | Apps Availability on Mobile Phone Platform, and Related Vocabulary Learning Strategies

Mobile Phone Platforms Vocabulary Learning Strategies

\begin{tabular}{|c|c|c|c|c|c|c|}
\hline Apps & $\mathrm{iOS}$ & Android & Web Based & $\begin{array}{l}\text { Dictionary } \\
\text { Use }\end{array}$ & $\begin{array}{l}\text { Phonological } \\
\text { Analysis }\end{array}$ & $\begin{array}{l}\text { Morphological Contextual Anal- } \\
\text { Analysis } \quad \text { ysis }\end{array}$ \\
\hline $\begin{array}{l}\text { The Free Dictio- } \\
\text { nary }\end{array}$ & $\mathrm{v}$ & $\mathrm{v}$ & $\mathrm{v}$ & $\mathrm{v}$ & $\mathrm{v}$ & $\mathrm{v}$ \\
\hline Dictionary.com & $\mathrm{v}$ & $\mathrm{v}$ & $\mathrm{v}$ & $\mathrm{v}$ & $\mathrm{v}$ & $\mathrm{v}$ \\
\hline Note: Apps are free & & & & & & \\
\hline
\end{tabular}

The student mentioned on the advantages of having these mobile dictionary apps as he could access the information anywhere and anytime exemplifying on minimizing the weight of the hard copy ones as references that should be carried, as long as the mobile phone connected to the internet network.

"I can say that I prefer mobile dictionary apps, as I consider this dictionary is handy, because I do not have to bring heavy books, I mean thick dictionary which is heavy to bring. Not to mention when I want to find the meaning of a word in this hard copy dictionary, I have to find the word by flipping over the "Letter Sign" within this dictionary, which I consider timeconsuming. Different from the mobile dictionary apps, I just have to write down the word on the search window, and then I can get the definiton of the word, its synonym, antonym, and its example in sentences. This kind of portability reinforced the student to be flexible, practical, and personalized the learning process as this learning on the go was more convenient instead of the conventional ways."

Student also referred to the characteristic feature in the mobile phone when accessing the mobile dictionary apps like listening to the audio button in pronouncing the word. The headset made the language learning more user-friendly as listening could be performed while writing on the laptop.

"There are many features already within the mobile phone apps on the way the words are pronounced. There is an audio for the words searched, so I can imitate on the way of the word is pronounced."

Student also highlighted the specific learning benefit perceived while utilizing the dictionary apps in their mobile phone. The outcome expected whilst working on their vocabulary acquisition required less effort and time: It is more fast to be searched than using printed dictionary. Besides dictionary apps is easier and more attractive instead of printed dictionary. The student realized the storage capacity of the mobile phone, and particular vocabulary retrieval within the mobile apps having low error rates (Mohammad et al., 2013) were beneficial for

\section{REFERENCES}

Basal, A., Yilmaz, S., Tanriverdi, A., and Sari, L. (2016). Effectiveness of Mobile Applications in Vocabulary Teaching. Contemporary Educational Technology, 7(1):47-59.

Bell, S. (2010). Project-Based Learning for the 21st century: Skills for the future. The their vocabulary learning (inside and outside of class).

\section{CONCLUSION}

This study clearly shows that technological advance cannot be separated from the current process of English teaching and learning. Even though written reference sources still have a place for students, it cannot be denied that online reference sources have many advantages, both in terms of time consumption and ease of use. Hence, online dictionaries are far more attractive in regards of the characteristic features they have than written dictionaries which tend to be monotonous for students. Those online and downloadable dictionaries can facilitate their users to find the required vocabulary quickly and easily so that a designated project can be completed on time.

These downloadable dictionaries are also benefited their users in term of vocabulary mastery in the process of a language learning since they can set up their personalized learning strategies. By all means, this is in accordance with the purpose of language learning in the IR 4.0 era, where students can utilize technology and empower themselves to get maximum results. Moreover, it will be difficult for students to break away from gains of technological advancements, because it has been part of their daily life now and later. Ultimately, this will have an effect on improving the output of educational institutions in the future. Apart from the effects of technology that are not always good for children, the use of gadgets properly will have a good impact on the progress of education in Indonesia.

\section{ACKNOWLEDGEMENTS}

We would like to acknowledge Center for Research and Community Service (P3M), Politeknik Negeri Padang for providing DIPA Research Grant, year 2019, with the Research Contract No: 173/PL9.1.4/01.02/2019 dated 30 August 2019. 
Boustani, K. (2019). The Correlation between Translation Equivalence, as a Vocabulary Learning Strategy, and Tunisian EFL Learners' Speaking Anxiety. Languages, 4(1):19-19.

Chanprasert, C. and Hnin, P. H. (2013). The use of mobile technologies for language skill development. Executive Journal, 34(1):98-107.

David, J. L. (2008). What Research Says About/Project-Based Learning. Educational Leadership, 65(5):80-82.

Deng, Q. and Trainin, G. (2015). Learning vocabulary with apps: From theory to practice. No Title. The Nebraska Educator, 2:49-69.

Efstratia, D. (2014). Experiential Education through Project Based Learning. Procedia - Social and Behavioral Sciences, 152:1256-1260.

Fisk, P. (2017). Education 4.0 ... the future of learning will be dramatically different, in school and throughout life.

Hanifah, N. (2016). Translation theory as a basic of translation learning: a qualitative-ethnographic study. Jurnal Cakrawala Pendidikan, 15(2):254-263.

Hussin, A. A. (2018). Education 4.0 Made Simple: Ideas For Teaching. International Journal of Education \& Literacy Studies, 6(3):92-98.

Ibrahim, S. M. (2018). Tantangan Pendidikan Era Revolusi Industri 4.0.

Kozinski, S. (2017). How generation $\mathrm{Z}$ is shaping the change in education.

Lan, Y.-F. and Sie, Y.-S. (2010). Using RSS to support mobile learning based on media richness theory. Computers \& Education, 55(2):723-732.

Larmer, J. and Mergendoller, J. R. (2010). Seven Essentials for Project-Based Learning. Educational Leadership, 68(1):34-37.

Lasse, D. (2019). Education and Industrial Revolution 4.0. Jurnal Handayani, 10(1):1-15.

Mackey, A. and Gass, S. M. (2005). Second Language Research. Lawrence Erbaulm Associates, Inc, New Jersey.

Mcdonough, J. and Steven, M. (1997). Research Methods for English Language Teachers. Great Britain; Arnold.

Mohammad, A. M. A., Rushdi, M., and Nimer, S. (2013). Using Mobile-Based Email for English Foreign Language Learners. TOJET: The Turkish Online. Journal of Educational Technology, 12(1):178-186.

Nation, I. S. P. (2008). Teaching and Learning Vocabulary. Heinle and Heinle, Boston.
Rachman, F. F. (2018). Apa itu revolusi industri 4.0.

Robinson, D. (2012). Becoming a translator: An introduction to the theory and practice of translation. London and New York. Routledge.

Steel, C. J. (2012). No Title. ASCILITE 2012 - Annual conference of the Australian Society for Computers in Tertiary Education, pages 875-880.

Stockwell, G. (2010). Using mobile phones for vocabulary activities: Examining the effect of the platform. Language Learning \& Technology, 14(2):95-100.

Suwantarathip, O. and Orawiwatnakul, W. (2015). No Title. The Turkish Online Journal of Educational Technology, 14(1):163-171.

Traxler, J. (2010). Medienbildung in neuen Kulturräumen (trs. Media literacy in new cultural spaces). Weisbaden: VS-Verlag für Sozialwissenschaft, pages 103-113.

Xu, M., David, J. M., and Kim, S. H. (2018). The Fourth Industrial Revolution: Opportunities and Challenges. Challenges. International Journal of Financial Research, 9(2):90-95.

Yaningsih, Y., Sariani, S., and Khairat, M. (2018). Having larger vocabulary size increases students' communicative competence producing spoken and written broadcasting script. Seminar Nasional Industri Bahasa.

Zhang, H., Song, W., and Burston, J. (2011). Reexamining the effectiveness of vocabulary learning via mobile phones. The Turkish Online Journal of Educational Technology, 10(3):203-214.

Conflict of Interest Statement: The authors declare that the research was conducted in the absence of any commercial or financial relationships that could be construed as a potential conflict of interest.

Copyright (c) 2020 Sariani, Yaningsih and El Khairat. This is an open-access article distributed under the terms of the Creative Commons Attribution License (CC BY). The use, distribution or reproduction in other forums is permitted, provided the original author(s) and the copyright owner(s) are credited and that the original publication in this journal is cited, in accordance with accepted academic practice. No use, distribution or reproduction is permitted which does not comply with these terms. 